\title{
Problemas ambientais no Brasil e a educação ambiental na formação do professor para o cidadão do campo
}

\section{Environmental problems in Brazil and environmental Education in teacher training for rural citizens}

Marcielen Oliveira Pantoja ${ }^{1}$, Raiane Ribeiro Cardoso ${ }^{1}$, Tatiane Cardoso de Souza ${ }^{2}$, Ataíde das Chagas Dias ${ }^{1}$, Magali Rosane Vasconcelos Ferreira ${ }^{1}$; Francilene Farias Valente Araújo ${ }^{1}$, Ediliane Quaresma Moraes Lobato ${ }^{3}$, José Francisco da Silva Costa ${ }^{1 *}$.

\section{RESUMO}

Esse artigo procura abordar os problemas ambientais no Brasil e a educação ambiental na formação do professor para o cidadão do campo que tem uma forte ligação com a natureza e por essa razão, todos devem ter essa aproximação para que possa valorizar a localidade e acima de tudo, adquirir o respeito pelo meio ambiente. Dessa maneira e levando em conta essa questão e diante dos problemas atuais, torna- se necessário construir um diálogo entre alunos e professores tendo em vista que o espaço escolar se constitui num excelente meio de transmissão de conhecimento e debate na construção e ampliação de compreender os problemas ambientais que a sociedade está passando. Para melhor desenvolver a pesquisa, desenvolvese um estudo teórico que destacam os principais problemas ambientais que acontecem a nível de Brasil, a saber, as queimadas por Biomas, desmatamento na Amazônia, poluição do solo e da poluição atmosférica. Justifica-se a abordagem, tendo em vista que os problemas ambientais atingiram proporção exorbitante com alterações climáticas significativas que tem como consequência, uma diminuição na qualidade de vida do ser humano. Paralelo a essa abordagem, desenvolve-se aeducação ambiental a partir de uma pesquisa de campo realizada no município de Abaetetuba na localidade do Rio Quainduba com cinco (5) professores da escola Dionísio Hage Num segundo momento, foi realizada a pesquisa de campo na Escola Dionísio Hage com aplicação de questionários com perguntas abertas de fundamental importância na elaboração das informações empíricas com intuito de identificar sobre a preocupação por parte dos professores quantos aos problemas ambientais e ao desenvolvimento de processos educacionais que estimulem suas práticas docente da educação ambiental. Conclui-se a pesquisa considerando que há evidência e empenho da aplicação e incorporação do tema meio ambiente em sala de aula e que os professores têm consciência de

\footnotetext{
${ }^{1}$ Universidade Federal do Pará, Abaetetuba, Pará -Brasil.

*E-mail: jfsc@ufpa.br

${ }^{2}$ Universidade do Estado do Pará, Moju, Pará - Brasil.

${ }^{3}$ Instituto Federal de Educação, Ciência e Tecnologia do Pará -Campus Abaetetuba, Pará Brasil.
} 
que a educação ambiental é importante para a formação social do indivíduo sendo aplicada de forma individual na escola avaliada, permeando as diferentes disciplinas do currículo escolar.

Palavras-chaves: Problemas ambientais; Brasil, Educação; Professor; Cidadão do campo.

\begin{abstract}
This article seeks to address environmental problems in Brazil and environmental education in teacher training for rural citizens who have a strong connection with nature and for that reason, everyone should have this approach so that they can value the location and above all, acquire respect for the environment. Thus, taking into account this issue and in light of current problems, it is necessary to build a dialogue between students and teachers, considering that the school space is an excellent means of transmitting knowledge and debate in the construction and expansion of understanding the environmental problems that society is going through. To better develop the research, a theoretical study is developed that highlight the main environmental problems that occur at the level of Brazil, namely, burning by Biomes, deforestation in the Amazon, soil and atmospheric pollution. The approach is justified, bearing in mind that environmental problems have reached an exorbitant proportion with significant climate change, which results in a decrease in the quality of life of human beings. Parallel to this approach, environmental education is developed from a field research carried out in the municipality of Abaetetuba in the locality of the Quainduba River with five (5) teachers from the Dionísio Hage school. Dionísio Hage using questionnaires with open questions of fundamental importance in the preparation of empirical information in order to identify the concern on the part of teachers regarding environmental problems and the development of educational processes that encourage their teaching practices in environmental education. The research concludes considering that there is evidence and commitment to the application and incorporation of the environment theme in the classroom and that teachers are aware that environmental education is important for the individual's social formation, being applied individually in the evaluated school. , permeating the different subjects of the school curriculum.
\end{abstract}

Keywords: Environmental problems; Brazil, environmental education; teacher; Country citizen.

\title{
INTRODUÇÃO
}

É evidente a importância de enfatizar a educação ambiental voltada para o cidadão do campo, pois o mesmo está em contato direto com a natureza, dessa forma é relevante que ele saiba realizar o manejo florestal corretamente para que seja garantida a manutenção dos produtos florestais madeireiros e não madeireiros, a proteção das águas, da fauna e da flora. Vale ressaltar também a importância benéfica que a floresta apresenta para sua saúde a partir das plantas medicinais e saber manuseá-las é essencial; entre outros benefícios.

Ademais, ele deve tomar conhecimento dos impactos ambientais que geram o desequilíbrio ambiental, provocados pela ação indevida do homem com o meio ambiente. É pertinente a necessidade da educação ambiental para as escolas do campo, pois o homem campesino ao ser incluído e instruído formalmente das questões ambientais poderá: construir e resinificar o conhecimento; associar os impactos que assolam a 
dimensão global/mundo e local/campo aos seus respectivos mentores; fomentar atitudes concretas de honestidade e respeito ao planeta.

Dessa maneira, para mostrar o quanto é importante valorizar e preservar o meio ambiente, o primeiro tópico desse artigo aborda um contexto dos problemas ambientais que acontecem no Brasil e o quanto está prejudicando o meio ambiente devido as grandes queimada, poluição atmosférica e hídrica que estão causando alterações climáticas significativas e devido a tudo isso, é necessário avançar no entendimento ecológico e na relação homem/natureza ou campo/natureza; submeter-se a um novo estilo de vida, a uma sustentabilidade possível.

Propostas inovadoras voltadas para a sustentabilidade devem estar inclusas nos projetos político-pedagógicos da educação para as comunidades do campo para que sejam formados cidadãos reflexivos, críticos e participativos que objetivem encontrar a solução dos problemas ambientais e contemplar novas relações entre os sujeitos da educação e os seus conhecimentos e tradições. Freire (1996) estabelece uma relação entre a questão ambiental e a educação, a política, a pobreza, a saúde e a ética, reforçando a necessidade de aproveitar a experiência de vida dos alunos para discutir problemas ligados à poluição, aos baixos níveis de bem estar das pessoas, dos lixões que conferem risco à saúde das populações.

O referido autor concebe a escola como uma instituição que não transforma a sociedade, mas pode ajudar a formar sujeitos capazes de fazer a transformação da sociedade, do mundo e de si mesmos. Portanto, é preciso que a escola localizada nas áreas rurais deixe de ser uma agência urbana no campo e se torne uma agência de transformação social apoiada num modelo pedagógico libertador, com conteúdo e métodos adequados à realidade da população local, equilibrando o "que e como" se ensina nas escolas e o "que e como" as famílias necessitam aprender. A educação ambiental é capaz de induzir dinâmicas sociais que levam a mudanças individuais e coletivas, locais e globais que provocam uma abordagem colaborativa e crítica na busca da resolução dos problemas.

Diante desse pressuposto, acredita-se que a Educação Ambiental pode contribuir para a formação emancipatória dos cidadãos do campo que se encontram, de certa forma, excluídos dos processos de transformação social, submetidos a aceitarem tudo o que é posto pelo sistema político- financeiro que rege nosso país. Entretanto, na escola, a Educação Ambiental só poderá contribuir para a formação emancipatória desses cidadãos, se for desenvolvida como uma prática diária e, por isso, precisa ser iniciada na 
sala de aula, por professores e estudantes, e aos poucos conquistar outros espaços da escola, pois desta maneira ajudará o educando a ampliar sua visão de mundo, permitindolhe, assim, fazer leitura crítica e reflexiva de seu ambiente natural e social.

Dessa forma, a presente pesquisa objetiva analisar a importância da educação ambiental na formação do professor para o cidadão do campo, bem como, analisar a formação do corpo docente da escola e identificar as disciplinas que foram base para a construção de conceitos referentes à educação ambiental; identificar conteúdos de educação ambiental nos planos de aula do professor; identificar as práticas de educação ambiental no cotidiano da escola; fomentar a discursão acerca dos benefícios do conhecimento em Educação Ambiental para o cidadão do campo.

Nessa abordagem, propõe-se analisar a atuação do professor em educação ambiental na Escola Dionísio Hage - Rio Quianduba, zona rural do município de Abaetetuba-PA, e refletir sobre sua formação e sua contribuição na formação dos alunos. Vale ressaltar que foram entrevistados os professores de cinco áreas diferentes, a saber Matemática, português, Ciências, Geografia e Pedagogia.

\section{APORTE TEÓRICO}

Esse tópico desenvolve sobre os principais problemas ambientais que acontecem no Brasil, destacando a questão das queimadas por Biomas, desmatamento na Amazônia, poluição atmosférica, poluição do solo o que traz à tona um problema de ordem mundial. Todavia, a razão do desenvolvimento desse tópico está intrínseca na questão que é preciso que cada comunidade, município, estado e pais venham adquirir uma maior conscientização quando se refere ao meio ambiente com intuito de preservar e lutar por uma mundo melhor em que cada ser humano possa dar as futuras gerações um lugar com uma maior qualidade de vida. Dessa maneira, esse tópico irá mostrar uma parcela dos muitos problemas ambientais que afetam de forma direta e indiretamente a qualidade de vida da população Brasileira.

\section{Os problemas ambientais atuais no Brasil}

Nunca o País passou por tantos problemas ambientais nos últimos 20 anos. Queimadas com destruições significativas de inúmeras espécies que se alastram por toda a região amazônica e que tem afetado o meio ambiente de forma múltipla com enorme gravidade, prejudicando todos os biomas. Entre as principais ameaças para meio ambiente 
estão a poluição da água, do ar e do solo, o desmatamento, o depósito e disposição de lixo em locais inadequados, entre outros (Valle 2004). Pesquisa realizada pelo Instituto Brasileiro de Geografia e Estatística (IBGE), aponta que 90\% dos municípios brasileiros apresentam problemas ambientais, e entre os mais relatados estão as queimadas, desmatamento e assoreamento, como supracitado no contexto anterior (IBGE, 2020).

No Brasil, a origem das queimadas no ambiente rural está relacionada com o meio de produção, que tem no manejo do fogo a solução mais rápida e econômica para geração de renda na agricultura (DE AVILA 20219; MAY, 2019). O aumento das taxas das queimadas na região amazônica possui estreita relação com o processo de desmatamento e manejo de áreas agrícolas e pecuárias, principalmente para a pecuária e o monocultivo de soja (FUCHS 2020).

O Brasil é o maior exportador mundial de carne bovina. Suas exportações atingiram o recorde de 1,64 milhão de toneladas em 2018 (fonte: Associação das Indústrias de Exportação de Carne no Brasil). Houve um crescimento muito mais intenso deste efetivo, e apesar da pandemia do COVID-19, e seus impactos na economia, as exportações do agronegócio brasileiro não foram afetadas negativamente (BRIZOLA et al., 2020). Os principais mercados consumidores são a China, seguida pelo Egito e União Europeia (MALAFAIA et al., 2020). A expansão da cultura da soja, também está sendo associada diretamente ao desmatamento da Floresta Amazônica.

Sua cultura iniciou-se no sul do país e avançou para a região central, sobre o bioma do cerrado, expandindo-se, gradativamente, ao norte do Brasil, principalmente por meio de latifúndios (FUCHS 2020). A área de avanço agrícola ao norte tem substituído o bioma local: a Floresta Amazônica, o que tem preocupado entidades públicas e privadas, em face do desmatamento exagerado e perda da biodiversidade e o aumento da ocorrência das queimadas (BARBER 2014).

Durante a combustão da matéria orgânica, libera-se o dióxido de carbono, principal gás de efeito estufa, representando cerca de $90 \%$ dos gases liberados (LASHOF, 1991). Desse modo, a queima de biomassa afeta não apenas a floresta a nível local, mas também o ciclo do carbono, influenciando as trocas radiativas terrestres e as mudanças no clima. A liberação de dióxido de carbono na atmosfera é um dos fatores mais importantes para o aquecimento global e atualmente o Brasil é o sétimo país que mais contribui para o nível de emissões de carbono no mundo, prejudicando, portanto, não só 
a saúde da população brasileira, como também da comunidade internacional (PADILLA et al., 2017).

\section{Queimadas por biomas}

No que diz respeito as queimadas por biomas, informações e análises da CNN feita com base nos dados do monitoramento de queimadas realizado pelo Instituto Nacional de Pesquisas Espaciais (Inpe) mostram que Cerrado, Caatinga, Pantanal, Amazônia e a Mata Atlântica contabilizaram mais focos de incêndios nos primeiros 23 dias de agosto do que os outros índices mensais do ano. $\mathrm{Ou}$ seja, cinco dos seis biomas brasileiros registraram mais queimadas em agosto do que nos outros meses de 2021.

Além disso, três desses biomas - Cerrado, Caatinga e Mata Atlântica contabilizaram de $1 .^{\circ}$ de janeiro até 23 de agosto de 2021 mais focos de incêndio do que o total registrado nos oito primeiros meses completos de 2020. No Cerrado, de $1 .^{\circ}$ de janeiro até 23 de agosto, foram contabilizados 27.542 focos de incêndio. Mesmo que o mês não tenha acabado, o total registrado neste período é maior que o contabilizado de 1. ${ }^{\circ}$ de janeiro até 31 de agosto de 2020: 24.205. Em menos de um ano, o crescimento de pontos de queimadas foi de $13,7 \%$. Apenas de julho para agosto, o total de focos cresceu $58,4 \%$, saltando de 6.955 para 11.019. Agosto de 2021 também apresentou crescimento de $8,5 \%$ quando comparado com o mesmo mês em 2020, que registrou 10.155 focos.

Já na Caatinga, os dados de $1 .^{\circ}$ de janeiro até 23 de agostos indicam 3.326 focos de incêndio. Esse número é 102,4\% maior do que os 1.643 registrados nos primeiros oito meses completos de 2020. Apenas nos primeiros 23 dias de agosto deste ano, os satélites do Inpe identificaram 1.216 pontos de queimadas - maior total mensal (mesmo que o mês não tenha acabado) em 2021. Quando comparado com o mês completo de agosto de 2020 ( 838 focos), neste ano o total cresceu $45,1 \%$. De julho para agosto, o total de focos cresceu $142,7 \%$, saltando de 501 para 1.216 .

No Pantanal a situação não está crítica quanto o ano anterior (pior na série histórica para o bioma e um dos episódios mais dramáticos no meio ambiente do país), mas apresentou uma piora de julho para agosto. Os focos de incêndio registrados no bioma saltaram de 508 para 1.336 de um mês para o outro, apresentando crescimento de $162,9 \%$. No ano passado, o total registrado em agosto foi de 5.935. O cenário é mais positivo no Pampa, que apresentou queda no número de focos de incêndio registrados em agosto deste ano em comparação com o mesmo mês em 2020: de 380 para 186, 
apresentando, portanto, diminuição de 51\%. Apenas neste ano, agosto contabilizou menos focos que julho (224) e maio (234), por exemplo.

Já na Amazônia, a situação é crítica e o bioma concentra o maior número de focos de incêndio entre os seis do Brasil. De 1. ${ }^{\circ}$ de janeiro até o dia 23 de agosto deste ano, foram registrados 33.668 focos de incêndio. Mesmo com dados apenas até o 23. ${ }^{\circ}$ dia, agosto de 2021 já acumula o pior índice mensal do ano: 22.301 pontos de queimadas. De julho para agosto, os focos registrados saltaram de 4.977 para 22.301, um crescimento de $348 \%$. No entanto, o bioma apresenta um cenário menos grave que o do ano anterior. Em agosto de 2020, foram 29.307 focos de incêndio e, no acumulado dos primeiros oito meses do ano, foram 44.013.

Na Mata Atlântica, 2021 contabilizou 10.634 focos de incêndio de 1..$^{\circ}$ de janeiro até 23 de agosto. Esse número é 9,9\% maior do que os 9.668 focos registrados ao longo dos oito primeiros meses completos de 2020. Segundo dados de áreas devastadas pelas queimadas em 2021, até julho deste ano o Inpe identificou $59.048 \mathrm{~km}^{2}$ afetados dentre os seis biomas brasileiros. Os dados são do mapa de área queimada elaborado pelo órgão. $\mathrm{O}$ bioma mais afetado foi o Cerrado, com $34.478 \mathrm{~km}^{2}$ queimados. Em seguida, estão a Amazônia, com $8.333 \mathrm{~km}^{2}$, e a Mata Atlântica, com $7.746 \mathrm{~km}^{2}$. A Caatinga aparece em quarto, com $5.378 \mathrm{~km}^{2}$, seguida pelo Pantanal, com $2.095 \mathrm{~km}^{2}$, e pelo Pampa, com 1.018 $\mathrm{km}^{2}$.

Quadro 1: Número de queimada por Bioma

\begin{tabular}{|c|c|}
\hline Bioma & Ano de 2021 \\
\hline Amazônia & $8.333 \mathrm{~km}^{2}$ \\
\hline Cerrado & $34.478 \mathrm{~km}^{2}$ \\
\hline Mata Atlântica & $7.746 \mathrm{~km}^{2}$ \\
\hline Caatinga & $5.378 \mathrm{~km}^{2}$ \\
\hline Pantanal & $2.095 \mathrm{~km}^{2}$ \\
\hline Pampa & $1.018 \mathrm{~km}^{2}$. \\
\hline
\end{tabular}

Fonte: Programa queimadas Inpe, 2021

\section{Desmatamento na Amazônia}

A Amazônia é a floresta mais extensa do planeta, distribuída através de uma área de aproximadamente 6,3 milhões de $\mathrm{Km}^{2}$ que abrange países como Brasil, Peru, 
Colômbia, Equador, Venezuela, Bolívia e Guianas. A parte que abrange o território brasileiro é de cerca de 5,5 milhões de $\mathrm{Km}^{2}$, sendo conhecida como Amazônia legal ou Amazônia brasileira, os estados que compõem a Amazônia legal são: Acre, Amapá, Amazonas, Pará, Rondônia, Roraima e Tocantins além de partes dos estados do Mato Grosso e Maranhão (ARANA, 2009).

As mudanças no padrão do uso do solo na região amazônica, principalmente a partir de 1970, têm sido bastante intensas, causando significativas modificações no clima da região (CORREIA; ALVALÁ; MANZI, 2006; ARTAXO et al., 2009; ROCHA; CORREIA; FIALHO, 2012). O desmatamento e as queimadas são os principais causadores desses impactos, pois emitem gases traços e partículas levando a alterações negativas no ciclo hidrológico da região amazônica (SILVA DIAS, 2006; COSTA; PAULIQUEVIS, 2009), tais como: diminuição do regime de chuvas, prolongação da estação seca na região e modificações nos processos de reciclagem de precipitação.

O desmatamento da floresta amazônica leva ao empobrecimento da biodiversidade na região, o ciclo hidrológico também é afetado podendo modificar drasticamente o transporte de umidade fornecido pela floresta para importantes regiões agrícolas do Brasil localizadas no sul e sudeste. Causando a supressão de chuvas não apenas em regiões brasileiras, mas em outras partes da América do Sul (FEARNSIDE, 2005).

Quadro 2: Desmatamento na Amazônia Brasileira por Estado.

\begin{tabular}{|c|c|c|}
\hline Estado & Km2 & Percentual \\
\hline Roraima & 617 & $6 \%$ \\
\hline Rondônia & 1245 & $13 \%$ \\
\hline Pará & 3862 & $40 \%$ \\
\hline Mato Grosso & 1685 & $17 \%$ \\
\hline Maranhão & 215 & $2 \%$ \\
\hline Amazônia & 1421 & $15 \%$ \\
\hline Acre & 688 & $7 \%$ \\
\hline
\end{tabular}

Fonte: Governo nega, mas novos dados de desmatamento confirmam "efeito Bolsonaro" (comentário) - Notícias ambientais (mongabay.com) 


\section{Poluição atmosférica}

No começo do século XX, o ar necessário para a respiração de todos os seres vivos da Terra ainda não era abordado de forma tão evidente, pois acreditava-se que este estaria constantemente disponível de forma a manter a vida no planeta (Russo, 2010). O número crescente da circulação de veículos no mundo e as atividades industriais são fatores que contribuem fortemente para a poluição da atmosfera (Cesar et al., 2013).

Novas fontes de poluentes, como a queima de combustíveis fósseis pelos motores, a combustão e a expansão das indústrias siderúrgicas ganharam força com a revolução industrial e isso ocorreu sem um acompanhamento dos possíveis danos que esses poluentes poderiam causar à saúde humana (Coelho, 2007; Mario, 2012). Diariamente podemos noticiar nos telejornais poluições excessivas na atmosfera, o que gera alteração na qualidade do ar, ocasionando danos à saúde humana.

Para Frank Hammes, CEO da IQAir, enquanto o novo coronavírus está dominando as manchetes internacionais, "um assassino silencioso está contribuindo para quase 7 milhões de mortes a mais por ano: “a poluição do ar”. Por meio da compilação e visualização de dados de milhares de estações de monitoramento da qualidade do ar, o Relatório Mundial da Qualidade do Ar de 2019 dá novo contexto à principal ameaça à saúde ambiental do mundo. (Frank Hammes).

Como observado no gráfico acima, foi realizada uma pesquisa durante a quarentena (2020) e antes da quarentena (2019) sobre a poluição atmosférica em várias cidades brasileiras, como em Curitiba, Paraná e foi comprovada significativa redução durante a quarentena. A pesquisa foi realizada pelo geógrafo e pesquisador Max Anjos que estuda, entre outros temas, o clima urbano e a poluição atmosférica.

Atualmente, ele coordena projeto de pesquisa que visa quantificar e mapear as emissões de dióxido de carbono $(\mathrm{CO} 2)$ das ruas de Curitiba no âmbito do programa internacional de pós-doutorado PRINT/CAPES, desenvolvido no Laboratório de Climatologia da Universidade Federal do Paraná (UFPR) e conta com a colaboração científica do Prof. Dr. Francisco Mendonça e da graduanda em Geografia Yasmin Forigo (Max Anjos 2019, Francisco Mendonça 2019, Yasmin Forigo 2019).

Vale enfatizar que os pesquisadores avaliaram as emissões de $\mathrm{CO} 2$ provenientes dos veículos motorizados, em algumas vias da capital do Paraná, no período de 20 a 29 de março de 2020 (durante a quarentena), e compararam com os resultados do mesmo período do ano de 2019. Os mapas mostram que os totais das emissões de CO2 durante a 
quarentena, no pico de fluxo de veículos, entre às $17 \mathrm{~h}$ e às $19 \mathrm{~h}$, foram até 3.200 toneladas menor do que o mesmo pico em 2019 (sem quarentena), indicando uma redução significativa de 54\% nas emissões. Se considerarmos a soma total das emissões por dia da semana, em todas as vias analisadas, essa redução chega aos surpreendentes $78 \%$.

\footnotetext{
"Apesar de serem preliminares, os resultados apresentados indicam que as medidas de confinamento e diminuição do fluxo de veículos nas ruas, devido à pandemia do COVID-19, reduziram drasticamente as emissões de CO2, o principal gás de efeito de estufa"' (Max Anjos).
}

Dessa forma, é notório a elevada poluição da atmosfera proveniente da queima de combustíveis em veículos automotores. Teixeira et al (2008) afirma que as emissões causadas por veículos automotores carregam uma grande variedade de substâncias tóxicas, as quais quando em contato com o sistema respiratório, podem ter os mais diversos efeitos negativos sobre a saúde. Essas emissões, devido ao processo de combustão e queima incompleta do combustível, são compostas de gases como: óxidos de carbono ( $\mathrm{CO}$ e $\mathrm{CO} 2$ ), óxidos de nitrogênio ( $\mathrm{NOx}$ ), hidrocarbonetos ( $\mathrm{HC}$ ), dentre os quais estão alguns considerados cancerígenos, óxidos de enxofre (SOx), partículas inaláveis (MP10), entre outras substâncias.

Azuaga (2000) afirma que entre os danos ao ambiente e à saúde humana, causados pela emissão desses poluentes, destacam-se a acidificação de rios e florestas, o ataque aos materiais, o aumento de problemas respiratórios e circulatórios na população, bem como a perda de bem estar da população, além do efeito estufa e do aquecimento global. Notase que os danos provenientes da poluição atmosférica não se restringem somente às áreas onde ocorreu a emissão, pois através da dispersão por meio das correntes de ar, as partículas e gases ultrapassam fronteiras regionais e nacionais.

\section{Poluição do Solo}

O resíduo sólido é todo e qualquer resto de material proveniente das atividades humanas com características especificas, que podem ser reciclados e empregado como matéria-prima de um novo produto/processo ou reutilizado. Eles podem ser encontrados nos estados sólido, líquido, semissólido e/ou gasoso, resultante das atividades industriais, hospitalar, comércio, serviços de limpeza urbana e domiciliar (MOTTA et al. 2009). Esses resíduos sólidos quando descartados de forma irregular gera desastres ambientais no solo. Estima-se que os resíduos sólidos urbanos descartados estão crescendo mais 
rapidamente que a proporção de crescimento populacional (REIS; CONTI; CORREA, 2015).

Dentre tantos resíduos, um dos maiores causadores de impacto ambiental no solo é o plástico. $\mathrm{O}$ acúmulo de dejetos plásticos no ambiente vem se tornando uma grande preocupação, gerando inúmeras consequências ao meio ambiente e afetando terra, rios e mares, sendo comprovado que quase 700 espécies de animais já foram afetadas por esses dejetos (National Geographic, 2018).

$\mathrm{Na}$ tabela abaixo temos os 10 Países que mais geram resíduos plásticos (em toneladas/ano) e a destinação final dos rejeitos. O relatório da WWF compila números do Banco do Mundial e analisa a relação de mais de 200 Países com o plástico. Na lista de maiores geradores de resíduos do material, o Brasil aparece em $4^{\circ}$ lugar, com 11,3 milhões de toneladas produzidas anualmente, ficando atrás apenas dos Estados Unidos, China e Índia. Em média, o brasileiro produz 1 quilo de lixo plástico a cada semana. Ademais, o País só recicla $1,28 \%$ do total produzido, um dos menores índices da pesquisa e bem abaixo da média global de reciclagem plástica que é de $9 \%$. No Brasil, segundo dados do Banco Mundial, mais de 2,4 milhões de toneladas de plástico são descartadas de forma irregular, sem qualquer tipo de tratamento, em lixões a céu aberto. Outras 7,7 milhões de toneladas são destinadas a aterros sanitários.

\section{LOCAL DA PESQUISA}

No tópico anterior, verificaram-se os principais problemas ambientais que acontecem no Brasil. Nesse presente tópico, procura-se descrever uma parcela da história do Município de Abaetetuba e da comunidade onde se localiza a escola pertencente a na zona rural do referido município, mas especificamente no Rio Quianduba que representam os cenários onde será realizada uma pesquisa de campo com professores para verificar a questão de uma educação ambiental, tão importante e necessária para o cidadão do campo.

\section{A cidade de Abaetetuba}

Abaetetuba é um município do estado do Pará, no Brasil. Pertence à Microrregião de Cametá, que por sua vez, integra a Mesorregião Nordeste Paraense (Figura 1) Sua população em 2021 está estimada em 160.439 habitantes. É a cidade-polo da Região do Baixo Tocantins e a $7^{\mathrm{a}}$ mais populosa do Estado. Nos seus limites administrativos estão 
os municípios de Moju, Barcarena e Igarapé-Miri. Abaetetuba se situa a $51 \mathrm{~km}$ a SulOeste de Belém. Situado a 22 metros de altitude, Abaetetuba tem as seguintes coordenadas geográficas: Latitude: $1^{\circ} 43^{\prime} 46^{\prime \prime}$ Sul, Longitude: 48 52' 27" Oeste.

Figura 1- A imagem mostra o município de Abaetetuba-PA.
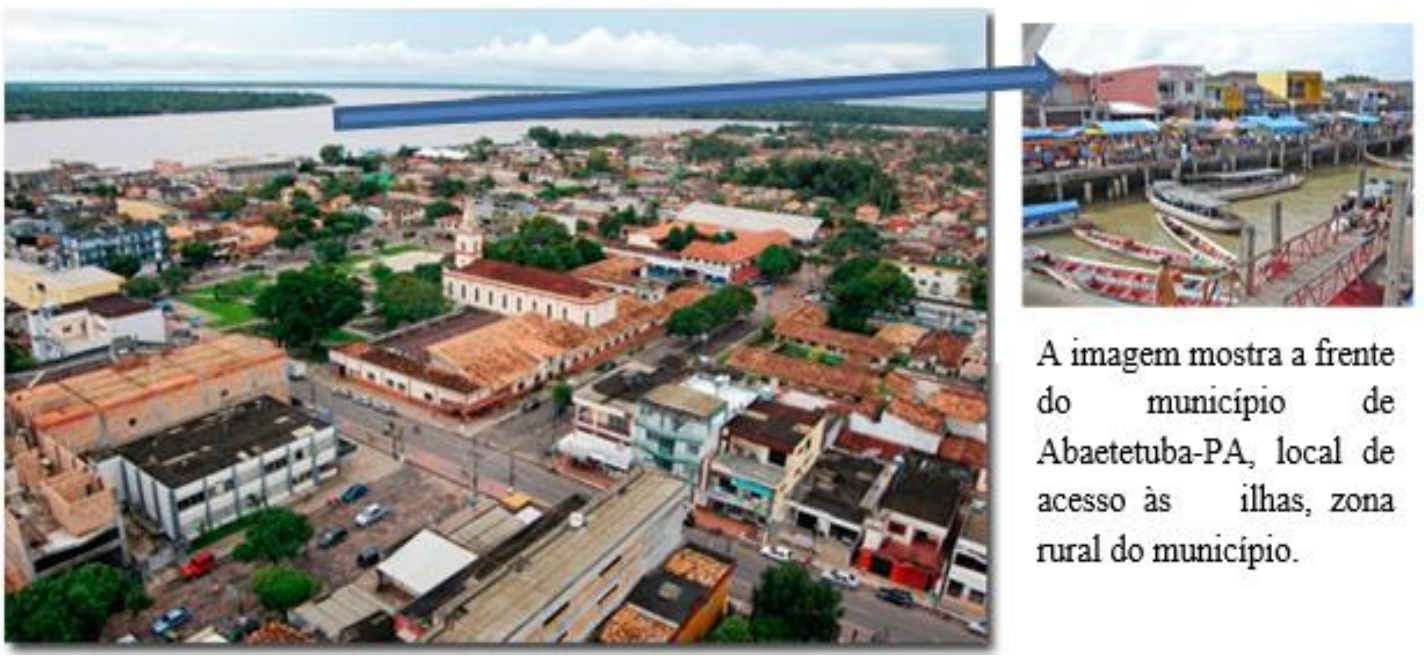

A imagem mostra a frente do município de Abaetetuba-PA, local de acesso às ilhas, zona rural do municipio.

Fonte: https://i.ytimg.com/vi/gqOMtBjRILU/maxresdefault.jpg

O município está localizado às margens do Rio Maratauíra, um afluente do Rio Tocantins. O Município compreende dois distritos: Abaetetuba, sede do mesmo e a Vila de Beja. É um dos municípios paraenses que tem o privilégio de possuir uma cultura própria muito forte. $\mathrm{O}$ distrito de Beja foi o berço da colonização de Abaetetuba. Por volta de 1635, padres capuchinhos vindos do Convento do Una, em Belém, após percorrerem os rios da região, juntaram-se a uma aldeia de tribos indígenas nômades. O aglomerado foi chamado de "Samaúma" e, depois, batizado de "Beja" pelo governador Francisco Xavier de Mendonça Furtado. (Google)

Embora Francisco de Azevedo Monteiro seja considerado, no imaginário popular, o fundador, pois chegou para tomar posse desse território como proprietário de uma sesmaria. Na beira do rio Maratauíra, num local protegido das marés pela ilha de Sirituba e nas proximidades do sítio Campompema e da Ilha da Pacoca, fundou um pequeno povoado, em 1724. O município de Abaetetuba foi desmembrado do território da capital do Estado, Belém, em 1880, de acordo com a Lei 973, de 23 de março, que também constituiu o município como autônomo. Um ano depois, em 1881, o presidente interino da Câmara em Belém, José Cardoso da Cunha Coimbra, instalou, no município, 
a Câmara Municipal de Abaeté. Por meio do Decreto-Lei 4 505, de 30 de dezembro de 1943, foi instituído o nome "Abaetetuba".

O nome primitivo do município era "Abaeté", que, na língua tupi, significa "homem verdadeiro", através da junção dos termos abá (homem) e eté (verdadeiro). Por meio do Decreto-lei 4 505, de 30 de dezembro de 1943, foi-lhe acrescentado o sufixo "tuba", oriundo do termo tupi tyba (ajuntamento), para diferenciá-lo do município homônimo no estado de Minas Gerais. Portanto, "Abaetetuba" significa, na língua tupi, "ajuntamento de homens verdadeiros". O município possui uma rede hidrográfica bastante vasta, navegável em quase toda a sua extensão. Existem cerca de 72 ilhas que constituem a chamada Região das Ilhas. O clima é comum da Amazônia, equatorial e super-úmido. Registra-se no município a existência de florestas de terra firme e florestas de várzeas.

\section{A Escola Municipal e Estadual Dionísio Hage}

A escola está localizada na zona rural do município de Abaetetuba, mas especificamente no Rio Quianduba, foi fundada no ano de 1997, para atender alunos da localidade e das redondezas do interior (Figura 2). A priori, era uma escola que funcionava em um barracão com poucas salas, porém no ano de 2005 o prefeito da época os presenteou com um prédio novo em alvenaria. Hoje a escola possui 15 salas de aula, 23 funcionários, sala de diretoria, laboratório de informática, sala de recursos multifuncionais para atendimento educacional especializado (AEE), cozinha, banheiro fora do prédio, sala de secretaria.

Figura 2: Escola localizada em área ribeirinha

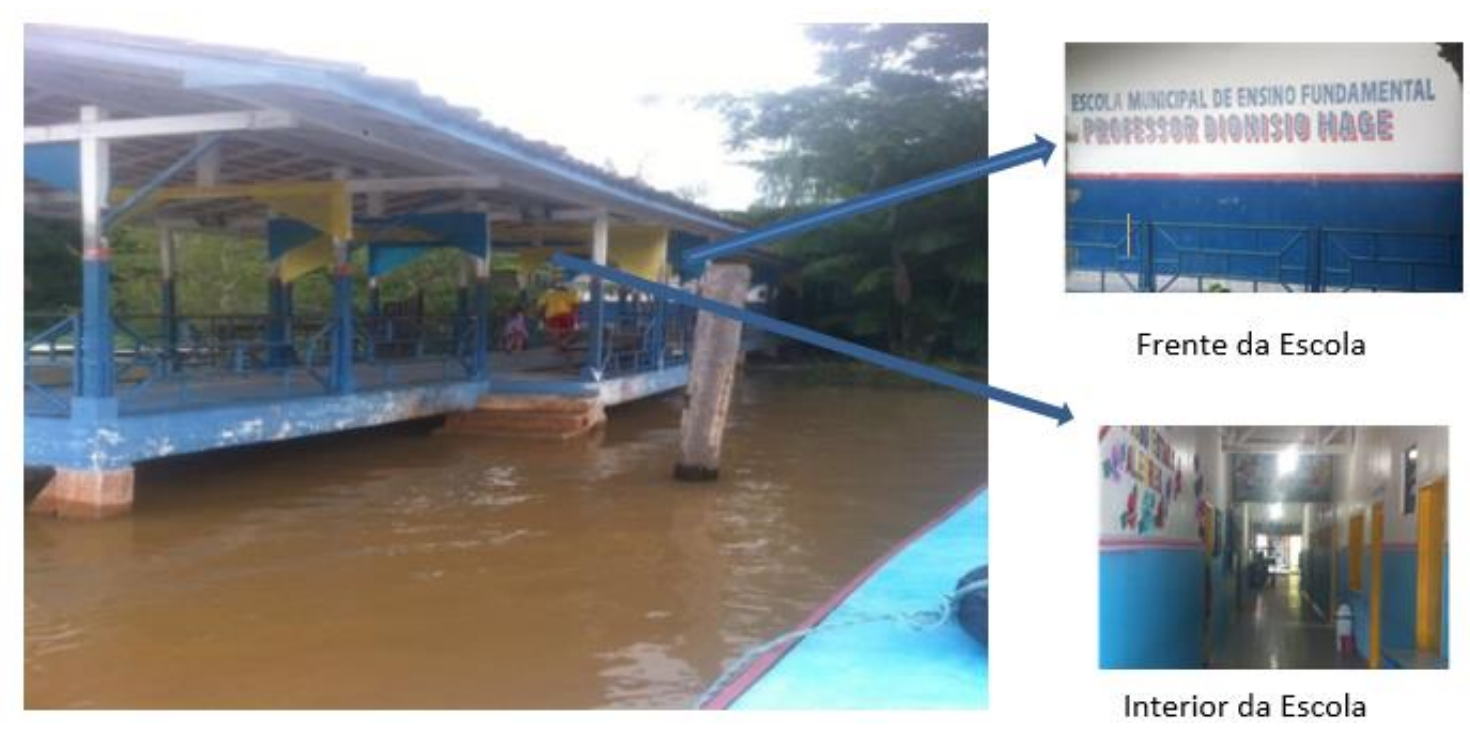

Fonte: Acervo dos autores 
A escola foi construída em área de várzea, onde parte do ano fica sobre as águas respeitando a dinâmica da paisagem amazônica. A escola possui 8 turmas do município e 19 turmas do estado, divididas em dois turnos: manhã e tarde. Uma equipe de 20 professores compõe o quadro docente e, do total atuante, cinco responderam ao questionário, das áreas de Língua Portuguesa, Geografia, Matemática, Ciências e Pedagogia. Dos cinco docentes, quatro residem na zona urbana e um na zona rural.

\section{METODOLOGIA DA PESQUISA}

A pesquisa foi desenvolvida com a utilização de estudos teóricos realizados através de uma bibliografia especializada e selecionada. Os procedimentos metodológicos foram divididos em três etapas.

Num primeiro momento, foi necessária uma ampla revisão bibliográfica sobre a temática a fim de estabelecer as bases teóricas norteadoras da pesquisa. Para isso, utilizouse da abordagem qualitativa com a utilização do método da pesquisa ação que possibilita que o pesquisador intervenha dentro de uma problemática social. Este método auxilia no entendimento do fenômeno de maneira a desenvolver descrições e interpretações explicativas da realidade local, desenvolvendo pesquisas exploratória, explicativa e descritiva.

Tecendo considerações a respeito deste tipo de pesquisa, Minayo et al. (1994) afirmam que esta responde a questões muito particulares, preocupando-se com um nível de realidade que não pode ser quantificado. Assim, a pesquisa qualitativa trabalha com o universo de significados, motivações, aspirações, crenças, valores e atitudes. Dedica-se àquilo que corresponde a um espaço mais profundo das relações, dos processos e dos fenômenos que não podem ser reduzidos à operacionalização de variáveis.

A variável qualitativa segundo Almeida (1989)

É uma variável que se refere a uma característica ou atributo da pessoa e não pode ser manipulada ou é de difícil de ser manipulada. As variáveis que indicam características humanas como sexo, educação, status, atitude, são variáveis qualitativas. Elas são normalmente descritivas, mas podem ser quantificadas.

(ALMEIDA, 1989. p. 60)

Num segundo momento, foi realizada a pesquisa de campo na Escola Dionísio Hage - Rio Quianduba, zona rural do município de Abaetetuba-Pa. Nesta fase foram 
aplicados questionários com perguntas abertas para 5 (cinco) professores de diferentes formações que foi de fundamental importância na elaboração das informações empíricas presente na construção do trabalho.

Segundo Parasuraman (1986), o questionário é muito importante na pesquisa científica, especialmente nas ciências sociais. Para Gressler (2004), a maior vantagem do questionário é a sua versatilidade, além disso, assegura maior liberdade para expressar opiniões. Já o terceiro e último momento compreendeu a sistematização do projeto. Nesta fase foram despendidos esforços no sentido de construir a análise final considerando a associação entre os aspectos de natureza empírica e os aspectos de natureza teórica adotado na fase inicial.

\section{RESULTADOS E DISCUSSÕES DA PESQUISA}

Foram analisados e avaliados os questionários aplicados aos 5 professores da escola de diferentes áreas de ensino, dentre elas Língua Portuguesa, Geografia, Pedagogia, Matemática e Ciências. Esse questionário é composto de 8 (oito) perguntas abertas (subjetivas).

Quanto aos questionários respondidos pelos educadores, pode-se verificar que há certa falta da inserção de disciplinas voltadas para a educação ambiental durante a formação dos professores, e que os mesmos percebem a grande relevância a este tema na localidade em que lecionam, porém não trabalham com a interdisciplinaridade voltada para o ensino da educação ambiental.

A finalidade da aplicação do questionário foi o de identificar, junto aos professores, suas práticas pedagógicas voltadas para a educação ambiental advindas de suas formações, de incentivos do governo, direção escolar, demais professores, entre outros, uma vez que é claro, em suas falas, a necessidade de realizar um trabalho de conscientização ambiental na localidade em que a escola está inserida.

\section{Formação e tempo do trabalho educacional}

Os resultados obtidos estão descritos de acordo com as perguntas realizadas e suas respostas e serão apresentados a seguir (Gráficos 1 e 2). 
Gráfico 1: Idade e tempo de formação dos professores entrevistados.

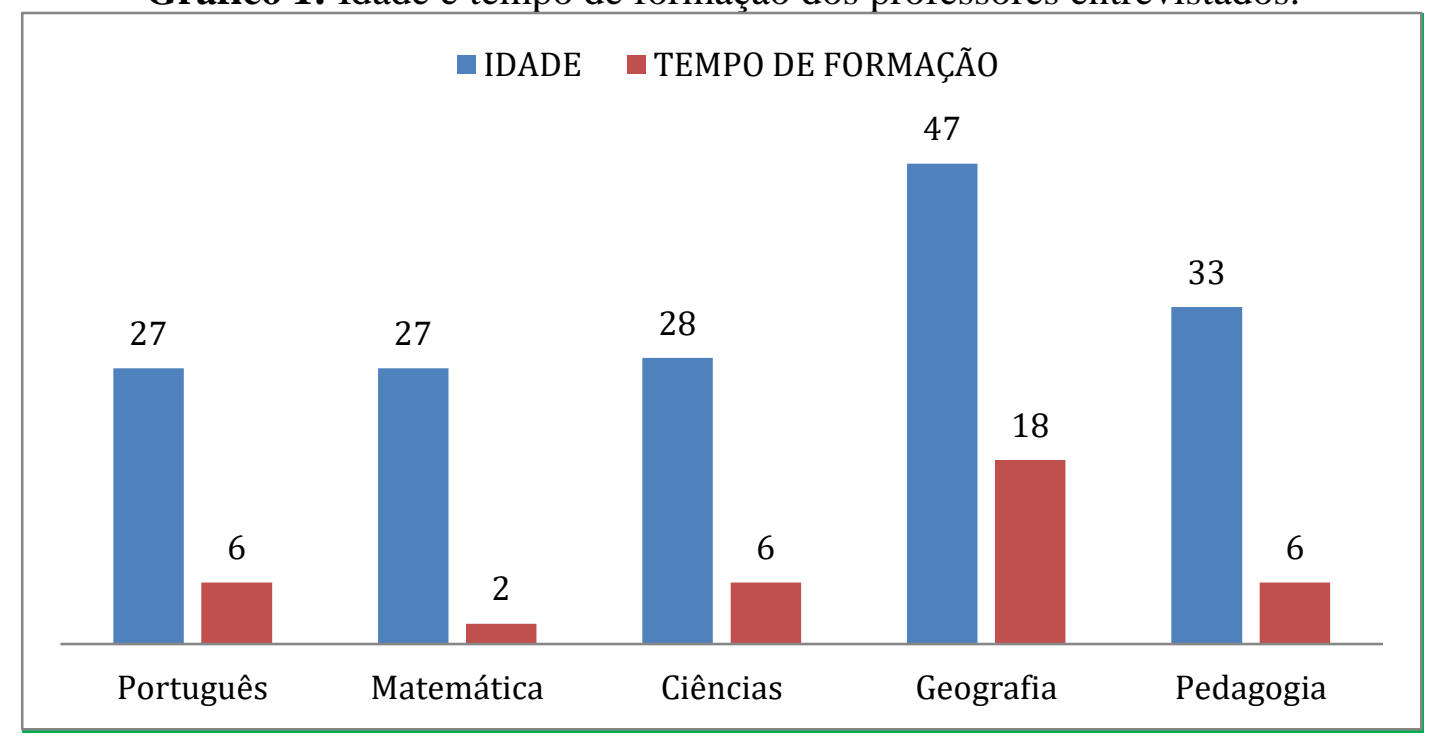

Fonte: Acervo dos autores

Gráfico 2: Tempo de trabalho na escola

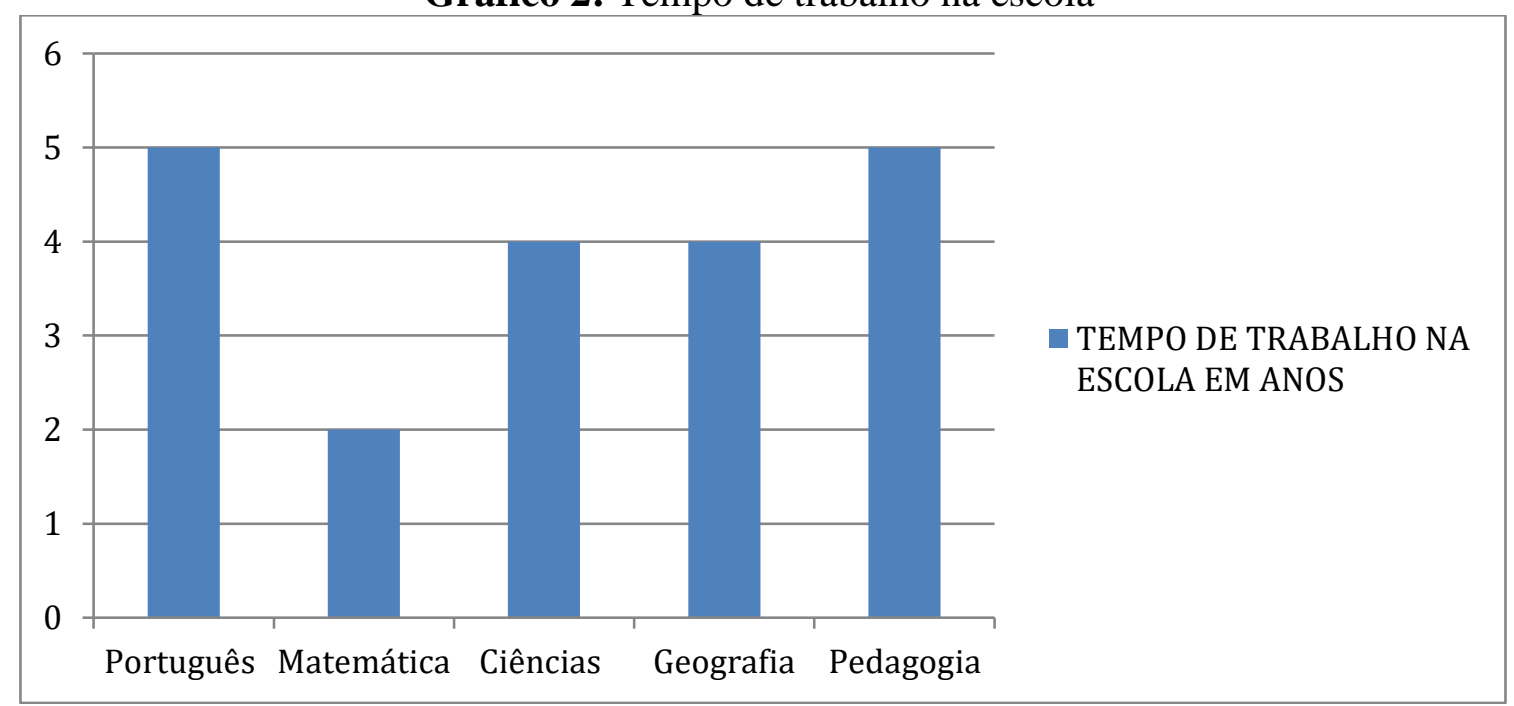

Fonte: Acervo dos autores

Os professores entrevistados possuem formações diferentes, pois a Educação Ambiental deve ser trabalhada em todas as disciplinas, em diferentes contextos. A Interdisciplinaridade pressupõe basicamente:

(...) uma intersubjetividade, não pretende a construção de uma superciência, mas uma mudança de atitude frente ao problema do conhecimento, uma substituição da concepção fragmentária para a unitária do ser humano. (FAZENDA, 2002, p. 40).

A Interdisciplinaridade é um termo utilizado para: 
(...) caracterizar a colaboração existente entre disciplinas diversas ou entre setores heterogêneos de uma mesma ciência (Exemplo: Psicologia e seus diferentes setores: Personalidade, Desenvolvimento Social etc.). Caracteriza-se por uma intensa reciprocidade nas trocas, visando um enriquecimento mútuo. (FAZENDA, 2002, p. 41).

A abordagem interdisciplinar pretende superar a fragmentação do conhecimento. Entretanto, esse é um importante viés a ser perseguido pelos educadores ambientais, onde se permite, pela compreensão mais globalizada do ambiente, trabalhar a interação em equilíbrio dos seres humanos com a natureza. Embora as distinções terminológicas sejam inúmeras, o princípio delas é sempre o mesmo. Conforme Japiassú (apud FAZENDA, 2002, p. 25), a Interdisciplinaridade caracteriza-se pela intensidade das trocas entre os especialistas e pelo grau de integração real das disciplinas no interior de um mesmo projeto de pesquisa.

\section{Disciplinas cursadas relacionadas à educação ambiental}

Observa-se que há ausência de disciplinas relacionadas à Educação Ambiental durante a formação dos professores (Quadro 1), com exceção daquelas voltadas para o estudo do meio ambiente como a disciplina de Ciências e Geografia.

Quadro 1: Professores e a sua formação com a Educação Ambiental

\begin{tabular}{|c|c|c|c|c|}
\hline $\begin{array}{l}\text { PROFESSOR I } \\
\text { MATEMÁTICA }\end{array}$ & $\begin{array}{l}\text { PROFESSOR II } \\
\text { PORTUGUÊS }\end{array}$ & $\begin{array}{l}\text { PROFESSOR III } \\
\text { GEOGRAFIA }\end{array}$ & $\begin{array}{l}\text { PROFESSOR IV } \\
\text { CIÊNCIAS }\end{array}$ & $\begin{array}{l}\text { PROFESSOR V } \\
\text { PEDAGOGIA }\end{array}$ \\
\hline NÃO CURSOU & NÃO CURSOU & CURSOU & CURSOU & NÃO CURSOU \\
\hline
\end{tabular}

Fonte: Acervo dos autores

Na disciplina de Ciências a respondente afirmou que a maioria das disciplinas cursadas estavam relacionadas ao meio ambiente, já o respondente da área de Geografia respondeu que cursou apenas duas disciplinas voltadas para a educação ambiental: Geografia Rural e Biogeografia e Meio Ambiente. Quanto aos professores entrevistados das disciplinas de Pedagogia, Matemática e Língua Portuguesa, responderam que não cursaram nenhuma disciplina relacionada à Educação Ambiental.

Por ser uma proposta interdisciplinar, a Educação Ambiental não deve pertencer exclusivamente a nenhuma disciplina e nem departamento, mas relacionar-se com todas elas. A questão ambiental, como também outros temas contemporâneos, deverá ser tratada num contexto em que haja interação com as outras áreas do conhecimento convencional, a fim de estar presente em todas elas, relacionando-se com questões da 
atualidade, tais como: o desenvolvimento sustentável, mudanças no padrão de consumo, a preservação, conservação e recuperação ambiental, ressaltando-se que os bens naturais do planeta pertencem a toda a humanidade e que não será possível preservá-los por meio de políticas isoladas.

\section{Professores que residem na comunidade em que lecionam}

Dos cinco professores entrevistados apenas um professor da área de Pedagogia reside na localidade em que a escola encontra-se inserida, os demais são moradores da zona urbana tendo que se deslocarem todos os dias até a zona rural do município (Quadro 2).

Quadro 2: Relação de Professores que pertencem a comunidade

\begin{tabular}{|c|c|c|c|c|}
\hline $\begin{array}{l}\text { PROFESSOR I } \\
\text { MATEMÁTICA }\end{array}$ & $\begin{array}{l}\text { PROFESSOR II } \\
\text { PORTUGUÊS }\end{array}$ & $\begin{array}{l}\text { PROFESSOR III } \\
\text { GEOGRAFIA }\end{array}$ & $\begin{array}{l}\text { PROFESSOR IV } \\
\text { CIÊNCIAS }\end{array}$ & $\begin{array}{l}\text { PROFESSOR V } \\
\text { PEDAGOGIA }\end{array}$ \\
\hline NÃO & NÃO & NÃO & NÃO & SIM \\
\hline
\end{tabular}

Fonte: Acervo dos autores

Visto que é de fundamental importância que o professor, para trabalhar a educação ambiental, conheça a realidade do local, dos seus alunos, da comunidade, e esteja verdadeiramente inserido nesse contexto, portanto seria interessante que todos os professores fossem morador da localidade, tendo assim uma aproximação maior com sua realidade ambiental. Conforme Souza (2006),

Começam a haver várias iniciativas que procuram inserir a Educação do Campo na agenda política do Estado, surgindo, assim, inúmeras parcerias, experiências educativas e mudanças na estrutura política, econômica e social do país, tendo como principais sujeitos os trabalhadores rurais e a necessidade de criação de conhecimentos educacionais críticos, voltados aos próprios sujeitos do campo. (SOUZA, 2006, p. 30)

Portanto, a Educação do Campo deve contemplar um ensino voltado à realidade de seus alunos, em que o conteúdo curricular e as metodologias de ensino do professor devem ser adequados às necessidades e interesses dos alunos de zona rural, os quais precisam de um ensino que valorize, dentre outros aspectos, a cultura da criança que vive no campo e seu modo de vida.

Um professor que trabalha no meio rural deve conhecer o local em que o aluno vive para poder nele despertar a vontade de conhecer a região em que se encontra inserido 
e os aspectos culturais da população característica de seu meio; ainda, para que o aluno possa saber viver nesse espaço e, quando se tornar adulto, ser um trabalhador digno do campo, que conheça e saiba utilizar as riquezas de sua terra, o que não seria possível àquela criança que recebeu uma educação apenas pautada no currículo urbano. Além disso, a escola é o local no qual o aluno entrará em contato com realidades de outros lugares e terá acesso aos conhecimentos construídos socialmente na trajetória humana.

Gráfico 3: A localidade em lecionam e os problemas ambientais

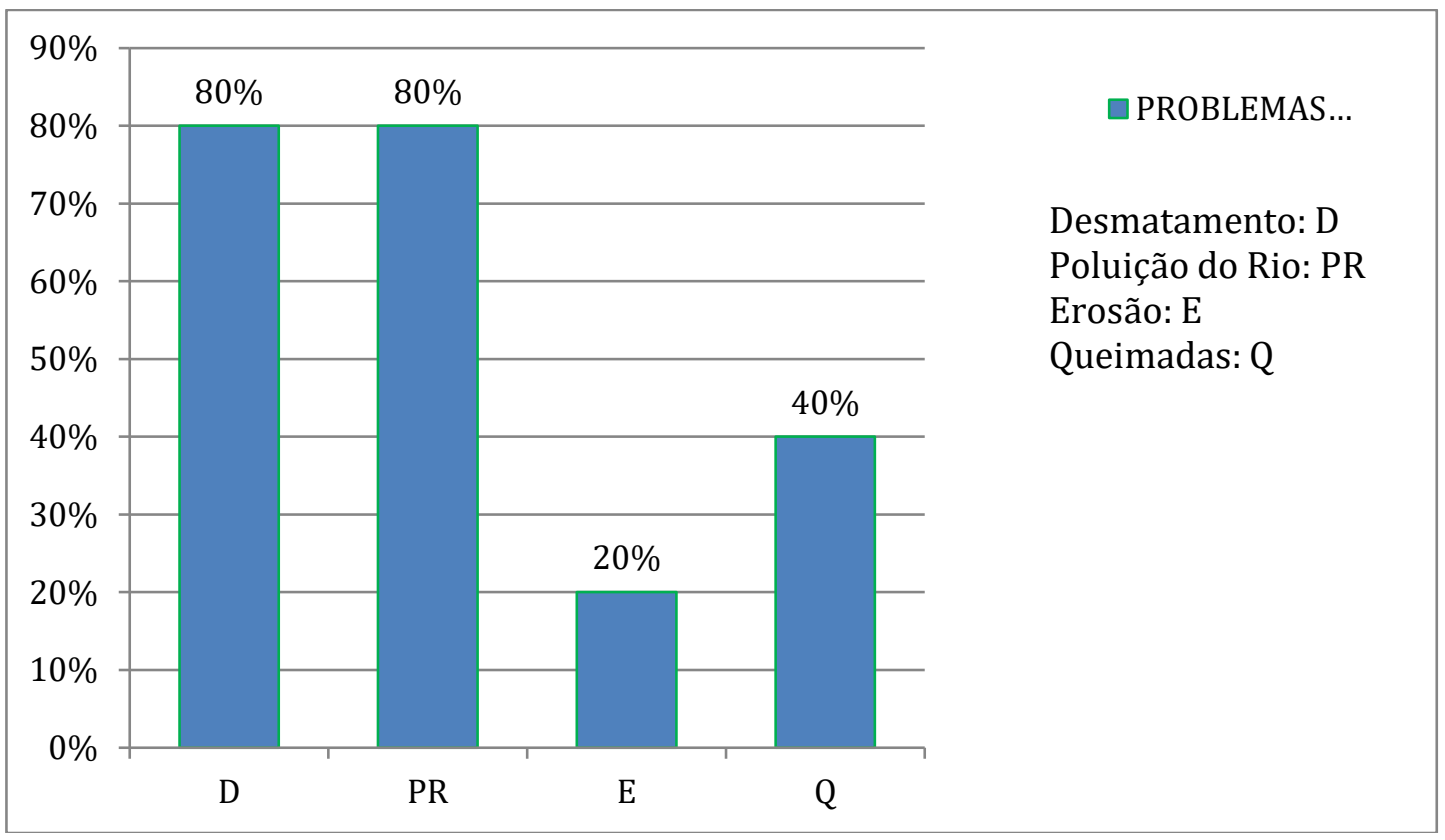

Fonte: Acervo dos autores

\section{Questionários aos professores}

Em relação ao questionário que declara sobre a questão dos problemas ambientais existentes na comunidade, os professores responderam que:

"Sim, os principais são: poluição do rio, desmatamento, fossas improvisadas, lixo nos quintais...". (P.Geografia)

"Sim, apresenta. Como desmatamento, queimada de áreas verdes, poluição dos rios, vazamento de óleo no rio das embarcações, etc.”. (P. Ciências)

Na verdade, os principais impactos estão relacionados com a poluição dos rios, a não coleta de seletiva do lixo e o despejo no rio (P. Pedagogia). 
A muito tempo observo que a comunidade necessita de uma educação ambiental de modo a valorizar a localidade, a saber o despejo de lixo nos rios, principalmente os eletrônicos que podem ocasionar problemas sérios de saúde para os que consumem a água do rio. (P. Língua Portuguesa)

"A comunidade precisa ter uma maior consciência do ambiente em que pertencem, principalmente quando tratar da questão das queimadas e da monocultura do plantio de açaizais que destruam outras espécies para tratar apenas do extrativismo. No problema das queimadas, alteram a riqueza do solo causada uma grande liberação de poluente ao meio ambiente"(P. matemática)

Nota-se que a localidade em que a escola está inserida, por apresentar diversos problemas ambientais, necessita de uma reeducação ambiental, e isso se torna possível através do ensino repassado pelos professores durante as aulas.

Segundo a UNESCO (2005, p. 44), "Educação ambiental é uma disciplina bem estabelecida que enfatiza a relação dos homens com o ambiente natural, as formas de conservá-lo, preservá-lo e de administrar seus recursos adequadamente".

Assim, incluindo a educação ambiental na escola pode-se preparar o indivíduo para exercer sua cidadania, possibilitando a ele uma participação efetiva nos processos sociais, culturais, políticos e econômicos relativos à preservação do "verde de sua localidade e do nosso planeta", que se encontram de certa forma em crise, precisando de recuperação urgente. $\mathrm{O}$ início do processo de conscientização, de que o meio ambiente solicita é o entendimento e a reflexão de uma condição básica para a convivência humana.

\section{O trabalho em sala de aula e as questões ambientais}

Sobre essa pergunta os professores responderam:

"Trabalho o meio ambiente junto ao dia a dia do aluno, utilizando a modelagem Matemática, para problematizar questões e fazer trabalhos acadêmicos" (P.Matemática)

"Sim, algumas vezes tento adequar minhas aulas com a realidade ambiental que vivemos, através de atividades lúdicas". (P.Pedagogia).

"O trabalho para a conscientização das questões ambientais é feito através de gêneros textuais, mais especificamente textos informativos com diferentes atividades sobre o assunto". Língua (P.Portuguesa).

Sobre a questão ambiental, procuro sempre contextualizar o conteúdo com intuito de resgatar a importância de valorizar a natureza e principalmente os rios que representam os meios de sobrevivência de muitas comunidades que diretamente dependem dele para o consumo diário. (P. Ciências) 
Como geografo, faço discussões a respeito do panorama em que vivem os alunos com objetivo de mostrar a questão de preservar o habitat e principalmente na tomada de conscientização e preservação das espécies nativas, impedindo as queimadas que empobrecem o solo e colocam em risco de extinção muitas espécies nativas (P. Geografia)

Os professores tentam adequar o trabalho das questões ambientais em suas aulas, porém durante os interrogatórios, eles deixaram claro que não recebem recursos, materiais de apoio, entre outros incentivos do governo municipal e/ou estadual para introduzir o trabalho de educação ambiental em suas aulas, ademais eles alegam que seria muito bom se tivessem esse tipo de apoio, até mesmo da escola. Para Guimarães "A educação ambiental deve ser um processo contínuo e permanente, iniciando em nível pré-escolar e estendendo-se por todas as etapas da educação formal ou informal”. (M. Guimarães)

Diante disso, Alves (1999) diz que: "há crianças que nunca viram uma galinha de verdade, nunca sentiram o cheiro de um pinheiro, nunca ouviram o canto do pintassilgo e não tem prazer em brincar com a terra. Pensam que a terra é sujeira. Não sabem que terra é vida".

\section{As atividades, projetos e educação ambiental}

Quando perguntados sobre essa questão foram obtidas as seguintes respostas:

\footnotetext{
"A instituição não possui nenhuma atividade ou projeto relacionado à educação ambiental. Na minha visão falta organização e interesse da parte da coordenação escolar, e seria de fundamental importância, uma vez que a escola localiza-se na área rural do município, especificamente área ribeirinha". (P.Português):

"Já existiu a horta na escola, porém não teve muito sucesso por conta da falta de interesse da direção e de professores das outras áreas de ensino. Hoje, a educação ambiental só é trabalhada em sala de aula ou em alguma atividade prática de algum assunto da disciplina de ciências" (P.Ciências)

"Em minha área de atuação não existe devido a falta de apoio da escola e coordenação". (P. Matemática)

"Não existe"(P. Pedagogia):

"Sim, há um projeto do "Mais Educação" chamado "Horta na escola", porém os recursos para tal finalidade são desviados para outros setores da escola. (P. Geografia).
}

Percebe-se a falta de projetos práticos relacionados à educação ambiental, esses projetos são de fundamental importância para serem desenvolvidos por professores de 
todas as disciplinas e trabalhados de forma interdisciplinar, contribuindo assim para mudanças de comportamento e concepções do cidadão da zona rural em relação ao meio ambiente que vivem.

Para Guimarães,

(...) a educação ambiental deve ser uma concepção totalizadora de educação e que é possível quando resulta de um projeto político pedagógico orgânico, construído coletivamente na interação escola e comunidade, e articulado com os movimentos populares organizados comprometidos com a preservação da vida em seu sentido mais profundo. Garcia (apud GUIMARÃES, 2000, p. 68).

As atividades realizadas em ambientes abertos, como na horta escolar, contribuem, dentre outros fatores, para os alunos compreenderem o perigo na utilização de agrotóxicos para a saúde humana e para o meio ambiente; proporciona uma compreensão da necessidade da preservação do meio ambiente escolar; desenvolve a capacidade do trabalho em equipe e da cooperação; e proporciona um maior contato com a natureza.

Proporciona também a modificação dos hábitos alimentares dos alunos, além da percepção da necessidade de reaproveitamento de materiais tais como: garrafas pet, embalagens tetras pak, copos descartáveis, entre outros. Tais atividades auxiliam no desenvolvimento da consciência de que é necessário adotarmos um estilo de vida menos impactante sobre o meio ambiente bem como a integração dos alunos com a problemática ambiental vivenciada.

Numa horta escolar há, ainda, a possibilidade de se trabalhar diversos temas, dentre os quais, os conceitos, princípios e o histórico da agricultura, a importância da educação ambiental e das hortaliças para a saúde, além das aulas práticas onde se trabalham as formas de plantio, o cultivo e o cuidado com as hortaliças (CRIBB, 2010).

\section{CONCLUSÃO}

Com este trabalho, procurou-se demonstrar a importância da educação ambiental na formação dos professores de diferentes disciplinas. $\mathrm{O}$ ensino das questões ambientais, no âmbito escolar, é primordial na vida do cidadão do campo, pois na escola eles aprendem um conjunto de valores essenciais para aumentar a capacidade de enfrentarem os problemas ambientais, bem como contribuírem para um desenvolvimento sustentável. 
A educação em todos os níveis, especialmente a educação universitária para a formação de professores, deve ser orientada para o desenvolvimento sustentável e para forjar atitudes, padrões de capacidade e comportamentos ambientalmente conscientes, tal como um sentido de responsabilidade ética.

Para Adams (2004), encarar os problemas ambientais é essencial, pois é do ambiente que depende a qualidade de vida da população. É preciso que as pessoas se conscientizem de preservar o meio ambiente, pois, isto sim, trará muitas melhorias em nossa qualidade de vida.

Da análise dos dados levantados e interpretados, ficam evidente que há uma preocupação por parte dos professores quantos aos problemas ambientais e ao desenvolvimento de processos educacionais que estimulem suas práticas docente da educação ambiental. Percebe-se que há o evidente empenho da aplicação e incorporação do tema meio ambiente em sala de aula. Ficou claro que os professores têm consciência de que a educação ambiental é importante para a formação social do indivíduo e com base na aplicação dos questionários conclui-se que a educação ambiental é aplicada de forma individual na escola avaliada, permeando as diferentes disciplinas do currículo escolar, havendo assim uma necessidade de interdisciplinaridade no ensino ambiental.

Por outro lado, observou-se, de acordo com o relato dos professores, que não há um esforço administrativo por parte da escola em disponibilizar aos alunos projetos atrativos que despertem a consciência ambiental nos mesmo, uma vez que não é viabilizado também, por parte do governo, condições para que tais projetos aconteçam como, disponibilizar recursos, materiais e espaços adequados para realização das atividades de educação ambiental. A escola é uma das instituições de maior alcance social e formadora de opinião, porém na instituição em questão, ainda há muito o que fazer em relação à problemática ambiental.

\section{REFERÊNCIAS}

ADAMS, Berenice Gehlen. Reciclando Conceitos. 2004.

ALMEIDA, J. A. Pesquisa em extensão rural: um manual de metodologia. Brasília: MEC/ABEAS, 1989.

AZUAGA. Danos ambientais causados por veículos leves no Brasil. Tese de mestrado em Engenharia - UFRJ, 2000. 
BARBER, C. P.; COCHRANE, M. A.; SOUZA JR, C. M.; LAURENCE, W. F. Roads, deforestation, and the mitigating effect of protected areas in the Amazon. Biological Conservation, 177, 203-209. 2014.

BENEDETTI, E. Água- Fonte da vida- Considerações. Veterinária Notícias, Uberlândia, v. 18, n. 1, p. 1-5, jan./jun. 2013.

BENETTI, A.; BIDONE, F. O meio ambiente e os recursos hidricos. IN: TUCCI, C. E. M. Hidrologia: ciência e aplicação. Porto Alegre: Ed. da Universidade/UFRGS/ABRH, 1995. p. 669.

BRISOLA, M. V. Os impactos sobre o agronegócio da carne bovina na Argentina e no Brasil: uma análise histórica e comparada. RIVAR (Santiago), v. 7, n. 19, p. 2243, 2020.

CESAR, G. C. A.; NASCIMENTO, C. F. L.; CARVALHO, A. J. Associação entre exposição ao material particulado e internações por doenças respiratórias em crianças. Revista de Saúde Pública, v.47, n.6, p.1209-12, 2013.

COELHO, S. Z. S. M. Uma análise estatística com vistas a previsibilidade de internações por doenças respiratórias em função de condições meteorotrópicas na cidade de São Paulo. 2007. Tese (Doutorado em Ciências) - Universidade de São Paulo. São Paulo, 2007.

CRIBB, S.L.de S.P. Contribuições da Educação Ambiental e Horta Escolar na promoção de melhorias ao ensino, à saúde e ao ambiente. REMPEC - Ensino, Saúde e Ambiente, v.3 n 1 p. 42-60 Abril 2010.

DE AVILA, S. R. S. Estudo exploratório sobre dinâmica do desmatamento em assentamentos localizados no território portal da Amazônia. Retratos de Assentamentos, v. 22, n. 1, p. 139- 152, 2019.

FARIAS, C. E. G. Mineração e o meio ambiente no Brasil. 2002.

FAZENDA, I. C. A. Integração e interdisciplinaridade no ensino brasileiro: efetividade ou ideologias. 5.ed. São Paulo: Edições Loyola, 2002.

FREIRE, P. Pedagogia da autonomia: saberes necessários à prática educativa. São Paulo: Paz e Terra, 1996.

FUCHS, V. B. Expansão de fronteira impulsionada pela China na Amazônia: quatro eixos de pressão causados pela crescente demanda pelo comércio de soja. CivitasRevista de Ciências Sociais, v. 20, n. 1, p. 16-31, 2020.

GRESSLER, L. A. (2004). Introdução à pesquisa: Projetos e relatórios (2. ed.). São Paulo, SP: Loyola.

GUIMARÃES, M. Educação ambiental: no consenso um embate?. Campinas, São Paulo: Papirus, 2000.

LOUREIRO, C.F.B. Trajetória e fundamentos da educação ambiental. São Paulo: Editora Cortez, 2004 
MACHADO, D.D.P.N.; GIOMBELLI, V. Educação Ambiental dos Empregados e a Certificação ISO 14000: um estudo de caso na companhia têxtil alfa. FURB, VI ENGEMA.

MALAFAIA, G. C.; BISCOLA, P. H. N.; DIAS, F. R. T. Os impactos da COVID-19 para a cadeia produtiva da carne bovina brasileira. Embrapa Gado de CorteComunicado Técnico (INFOTECA-E), 2020.

MEES, J. B. R. et al. Removal of organic matter and nutrients from slaughterhouse wastewater by using Eichhornia crassipes and evaluation of the generated biomass composting. Revista Engenharia Agrícola, v. 29, n. 3, p. 466-73

MINAYO, M. C. S. et al. Pesquisa Social: teoria, método e criatividade. Petrópolis: Vozes, 1994.

MOTA, J. C.; ALMEIDA, M. M. A.; AlENCAR, V. C.; CURI, W. F. (2009). Características e impactos ambientais causados pelos resíduos sólidos: uma visão conceitual. Congresso Internacional de Meio Ambiente Subterrâneo, I. Anais., 1-15 p.

NATIONAL GEOGRAPHIC. Para os bichos, o plástico transforma o oceano em um campo minado. 2018. PARASURAMAN, A. Marketing Research. Toronto: Addison Wesley Publishing Company, 1986.

REIS, M. F.; CONTI, M. D.; CORREA, M. R. M. (2015). Gestão de Resíduos Sólidos: Desafios e Oportunidades para a Cidade de São Paulo, RISUS. Journal on Innovation and Sustainability, 6 (3): 77-96.

RUSSO, P. R. A qualidade do ar no município do Rio de Janeiro : análise espaço- temporal de partículas em suspensão na atmosfera. Revista de Ciências Humanas, v.10, n.1, p.78-93, jan./jun. 2010.SOUSA, Rafaela. "Desmatamento na Amazônia"; Brasil Escola. Disponível em: https://brasilescola.uol.com.br/brasil/desmatamento-da-amazonia.htm. Acesso em 25 de novembro de 2021

SOUZA, M. A. Educação do campo: propostas e práticas pedagógicas do MST. Petrópolis: Vozes, 2006.

Stavins, R. (1998). Market-Based Environmental Policies. Discussion Paper 98-26 Resources for the Future. Retrieved December 10, 2009 from http://www.rff.org/Documents/RFFDP-98-26.pdf

TEIXEIRA, E. C; FELTES, S; SANTANA, E. R. R. Estudo Das Emissões De Fontes Móveis Na Região Metropolitana de Porto Alegre, Rio Grande Do Sul. Química Nova, Vol. 31, pag 244, 2008.

UNESCO. Década da Educação das Nações Unidas para um Desenvolvimento Sustentável, 2005-2014: documento final do esquema internacional de implementação, Brasília, Brasil, 2005. 120 p.

VALLE, C. E. Qualidade Ambiental: ISO 14000. 5 Ed. São Paulo/SP: SENAC, 2004.

VIEIRA, Andréia Costa; BARCELLOS, Ilma de Camargos. Água: bem ambiental de uso comum da humanidade. Direito Ambiental: conservação e degradação do meio 
ambiente. Título 2. Jan. - mar./2009. São Paulo: Editora Revista dos Tribunais, 2011. Pag. 68.

WWF / Banco Mundial (What a Waste 2.0: A Global Snapshot of Solid Waste Management to 2050).

Recebido em: 10/11/2021

Aprovado em: 05/12/2021

Publicado em: 09/12/2021 